\title{
O VALOR DOS POBRES: a aposta no dinheiro como mediação para o conflito social contemporâneo
}

\author{
Gabriel de Santis Feltran*
}

\begin{abstract}
No Brasil, as periferias são o centro de duas figurações recentes e dicotômicas: a da violência urbana que pede mais repressão e a do desenvolvimento social, que transformaria pobres em "Classe C". Este ensaio argumenta que a representação da "violência urbana" retirou o centro da "questão social" contemporânea dos "trabalhadores", deslocando-o aos "marginais". A derrocada do universalismo inscrito nesse deslocamento enseja um governo seletivo que recorta a população em distintos graus de "vulnerabilidade" e níveis de "complexidade" da intervenção estatal; como efeito colateral, emergem distintos regimes normativos nas periferias - por exemplo: estatal, do "crime" e religioso - que embora estejam sempre em tensão, encontram coesão no fato de regularem mercados monetarizados. O dinheiro passa a mediar a relação entre os grupos recortados e suas formas de vida que, sob outras perspectivas - a lei ou a moral - estariam em alteridade radical; o consumo emerge como forma de vida comum e a expansão mercantil, aposta de todos, conecta mercados legais e ilegais, inclusive fomentando a violência urbana que pretensamente controlaria.
\end{abstract}

Palavras-chave: Periferias. Violência. Desenvolvimento. Dinheiro. Valor.

\section{INTRODUÇÃO}

Em São Paulo, Deus é uma nota de cem. Racionais MC's, 2002

Nos últimos anos, foi intenso o debate entre cientistas sociais que estudam a pobreza, a "questão social" e as políticas voltadas para a proteção social ou para a repressão da marginalidade, bem como a criminalidade e a violência. ${ }^{1}$ Se nunca houve consenso na biblio-

1 Refiro-me às discussões que travamos entre colegas e estudantes, amigos e parceiros de trabalho que embasam esse ensaio, cujas ideias não são tão minhas quanto os equívocos que as acompanham. Agradeço aos pesquisadores do NaMargem, CEM, NEU-CEBRAP, CEVIS, NECVU, NACI, PAGU e GEVAC, além de Ernesto Isunza, Neiva Vieira, Cibele Rizek, Carly Machado, Vera Telles, Adriana Vianna, Daniel Hirata, Derek Pardue, Angelo Martins, Isabel Georges, Jacob Lima, Heitor Frugoli, Mariana Cavalcanti, Bela Feldman Bianco, Leonardo Sá e Mariana Cortes, além de Daniel Cefaï, Gabriel Kessler, Patrick Le Galès, Marie Morelle, Salvador Maldonado e Nicolas Bautes pela intensidade das trocas intelectuais desses últimos anos.

* Doutor em Ciências Sociais. Professor do Departamento de Sociologia da Universidade Federal de São Carlos (UFSCar). Coordenador Científico do Centro de Estudos da Metrópole (CEM) e pesquisador do Núcleo de Etnografias Urbanas do CEBRAP. Agradeço o financiamento da Fundação de Amparo à Pesquisa do Estado de São Paulo (FAPESP), através do processo $n^{\circ}$ 2013/07616-7 (CEPIDCEM), bem como da bolsa de produtividade PQ2 do CNPq. Rodovia Washington Luis, km235. Cep: 13565-905. São Carlos - São Paulo - Brasil. gabrielfeltran@gmail.com grafia brasileira especializada nesses grupos, ${ }^{2}$ recentemente suas vertentes pendularam entre argumentos tão consistentes, quanto divergentes. De um lado, enfatizou-se a expansão da cidadania, comprovada pela maior cobertura das políticas e melhoria dos indicadores sociais (inclusive desigualdade de renda), mas também pela manutenção de marcos legais progressistas, consolidação da participação social em conselhos, estabilidade da democracia institucional, além da enorme expansão das capacidades de consumo e crédito populares. ${ }^{3}$

${ }^{2}$ O lugar que os pobres ocupariam na democracia e nas cidades brasileiras, assim como a relação entre pobreza, desenvolvimento e cidadania, sempre foi tema central à bibliografia especializada, seja a de influência marxista (Kowarick, 1975; Oliveira, 1982), incluindo suas vertentes gramsciana (Dagnino, 1994, 2002; Silva, 1993) e thompsoniana (Telles\&Paoli, 2000; Sader, 1988), seja a mais culturalista (Durham, 2005; Caldeira, 2000) ou a de influência arendtiana (Telles, 2001) e habermasiana (Zaluar, 2004).

${ }^{3}$ Exemplar dessa vertente é a intensa produção do Centro de Estudos da Metrópole, dedicada a embasar, questionar, contrapor ou oferecer hipóteses alternativas, sempre amparadas em pesquisa empírica e utilizando métodos que vão da demografia à etnografia, uma série de argumentos correntes na bibliografia sobre o tema das desigualdades (Arretche, 2014), políticas sociais (Arretche, 2010; Marques, 2010, 2012; Kowarick\&Marques, 2011; Marques\&Bichir, 2011), relações de trabalho (Guimarães, 2009; 2012 b), território, cidade e pobreza (Marques, 2012), para além das estratégias estatais de governo do social (Feltran, 2011; 2012; Marques, 2014) e relações raciais (Guimarães, 2012a), entre diversos outros temas. 
De outro, denunciou-se o recrudescimento da insegurança e a militarização da ordem urbana, a criminalização da pobreza e sua instrumentalização pelos mercados imobiliários e de segurança privada, a ampliação do encarceramento e a tendência à internação compulsória de usuários de drogas, bem como a incriminação do protesto social, atentados aos direitos civis. ${ }^{4}$ Os mesmos fenômenos empíricos - por exemplo, os debates em torno de mudanças no Estatuto da Criança e do Adolescente, legalização das drogas, ações afirmativas, funk ostentação ou mesmo a queda de homicídios em São Paulo - podem ser tomados como indicadores de diagnósticos dos mais aos menos otimistas, tendo por base a consolidação da democracia ou o desenvolvimento econômico.

Sem dúvida, as perspectivas teóricas, os locais de observação e métodos empregados em cada vertente analítica conduzem a parte das divergências em pauta, no mais das vezes muito saudáveis ao amadurecimento do debate. Entretanto, sugiro que uma das causas centrais desse desentendimento é a demasiada agregação analítica, que pressupõe homogeneidade empírica ainda que afirmemos o contrário, que categorias como "pobreza", "periferia" ou "classes populares" carregam consigo. Essas palavras abrangem hoje, sem nos darmos clável à de um taxista; de uma travesti que faz Фึ่ programa na rua a um pedreiro com três carros na garagem; de meninas do interior trabalhani do no Hooter's para pagar faculdade na capital a um estudante secundarista cumprindo Liberdade Assistida; de uma ingressante por Ação i Afirmativa em uma boa universidade pública \& a um morador de rua, ex-presidiário e usuário ลे radical de crack; de um interno de Comunida$\therefore$ de Terapêutica que busca livrar-se da cocaína a um operário têxtil boliviano, quando não um 蒏

${ }^{4}$ De modos distintos, Telles\&Cabanes (2006); Rizek\&Oliveira (2007); Cabanes, Georges, Rizek, \& Telles (2011) ou Vieira\&Feltran (2013), além da producão recente do NECVU-UFRJ, do CEVIS-IESP/UERJ ou do Núcleo de Etnografias Urbanas do CEBRAP, sobretudo Rui, 2012; Fiore, 2013; Malvasi, 2012, são exemplares dessa vertente da bibliografia. vendedor ambulante nigeriano; de uma Agente Comunitária de Saúde evangélica a um pequeno empreendedor do ramo de automóveis, participante do Rotary Club; de um segurança privado "preto" de 60 anos, nordestino, a um presidiário "pardo" de 19, favelado; de um policial, um mecânico desempregado ou um dono de desmanches clandestinos. Sabemos, entretanto, que todos esses sujeitos poderiam, hoje, morar em uma mesma rua num bairro considerado de periferia e, tomadas as categorias ocupacionais ou de renda, todos poderiam ser considerados "integrantes das classes trabalhadoras". As perspectivas de vida de cada um, seus pertencimentos territoriais, familiares e religiosos, seus códigos de conduta e os programas sociais que chegam até eles, vindos de ONGs, governos ou igrejas, bem como os tipos de inscrição nos mercados e os modos como a "violência urbana" toca suas vidas, sendo por eles administrada, são muito divergentes.

Participando de uma série de debates sobre as periferias, os pobres, a violência, os movimentos sociais ou as transformações urbanas nos últimos anos, dei-me conta de que nossos argumentos, vindos de diferentes áreas e enfoques são, quase sempre, baseados em representações totalizantes sobre a "periferia" ou a "pobreza". Mais recentemente, tenho percebido que quase sempre tomamos uma imagem particular - a do integrante do Primeiro Comando da Capital - PCC, do usuário de crack, do presidiário, ou a das famílias endividadas que compram carros ou apartamentos da MRV Engenharia, financiados pela Caixa - como a parte que representaria o todo das periferias, suas tendências violentas ou de inserção mercantil.

Este artigo não toma como pressuposto da análise, mas como objeto de reflexão esse modo totalizante e quase sempre dicotômico de perceber os pobres como recortados entre as perspectivas da "violência urbana" e do "desenvolvimento econômico". Assim, escrevo a partir da minha experiência situada, ao mesmo tempo intelectual e política, vivida nos últimos anos em inúmeros debates sobre 
as "periferias" - sigo utilizando o termo como uma representação a compreender. A heterogeneidade dos setores populares e os recortes populacionais neles produzidos pelos programas sociais, pelas igrejas, pelo "mundo do crime", são aqui pontos de partida da reflexão. A minha pesquisa nas periferias de São Paulo, portanto, não é sua única fonte de dados; a etnografia (tradução de uma experiência vivida em texto) segue sendo, entretanto, o modo de conhecimento que a embasa.

A argumentação pressupõe fronteiras tensas entre setores populacionais das "periferias", classificados como "Classe C" ou "marginais", mas, sobretudo, entre eles e grupos sociais mais abastados (entendidos por todos esses como "playboys", "madames" ou "bacanas"). São essas as duas linhas de conflito social que me interessa estudar, na base dos recortes populacionais. Os modos de governo desse conflito, que produz ordem social e urbana, tornam-se então objetos privilegiados para a análise. Como hipótese, penso que hoje o conflito social não seria apenas mediado pelos valores cristãos, pilar da coesão entre desiguais no Brasil, ou pela ascensão do direito como mediador privilegiado (a lei, a ordem, a cidadania); tampouco seria redimido apenas no coração da lógica punitiva, exemplar do encarceramento massivo e da criminalização da pobreza que tenta assujeitar à força os descontentes. As estratégias governamentais contemporâneas parecem estar baseadas, justamente, na variação situacional de um repertório de regimes de governo realmente existentes e relativamente autônomos (Silva, 1993; Feltran 2010, 2011, 2012; Grillo, 2013), que incluem essas estratégias e tantas outras, organizadas a partir de recortes populacionais tão mais precisos quanto possível. Entre esses recortes essencializados em corpos e palavras, figura-se a ideia de que apartação nos planos da moral ou da lei. Entretanto, é nítido que todos eles estão submetidos à uma lógica mercantil formalmente integrada pela monetarização, o que produz uma forma de vida comum, desejável por todos, centrada na expansão do consumo. Se são figurados como vivendo em universos morais distintos, trabalhadores e bandidos trocam bens e serviços monetarizados entre si, na medida em que os mercados que operam encontram-se profundamente vinculados; policiais e traficantes também têm seus acertos, e só podem ser financeiros, para que o tráfico possa operar com benefício para ambos; playboys e manos adoram as mesmas motos e carros, submetendo-se a inúmeras relações diretas nas distintas posições dos mercados de trabalho e consumo que ocupam. Todos respeitam a riqueza como signo de status. $\mathrm{O}$ dinheiro é objetivamente elevado ao estatuto de forma mediadora entre grupos populacionais em conflito, suplantando em muito a legitimidade da lei e da moral, que invariavelmente os afastariam.

Esquadrinhar a "população" e essencializar os recortes produzidos, objetivando-os, seria a função primeira da maquinaria de governo; a partir dessa classificação, pode-se produzir valoração seletiva e desigual de recortes populacionais produzidos. O valor atribuído a cada recorte, devidamente objetivado nessas classificações, pode, em seguida, ser monetarizado (Simmel, 1900)..$^{5}$ Lógica de mercado, portanto - assim se faz com o solo urbano, que se recortam os "nichos de mercado"; assim também se deve agora recortar as populações, tornadas ao mesmo tempo "público-alvo" de marqueteiros e programas de governo. ${ }^{6}$ Daí o nexo constitutivo entre o governo seletivo da pobreza e o desenvolvimento mercantil, daí o ideal de expansão de consumo aos pobres e sua integração aos mercados como projeto político fundamental. É a ampliação da circula-

${ }^{5}$ A reflexão é inspirada pelas reflexões de Simmel (2014) e Arendt (2001) sobre a monetarização dos objetos culturais, precedida pelo trabalho de tornar plausível a pergunta "quanto custa?", até então impensável para esses objetos, como hoje seria perguntar "quanto custa seu filho?".

${ }^{6}$ Sintomático, assim, que um Secretário Municipal de Segurança, em conversa pessoal, tenha se referido por três vezes ao "Crack, é possível vencer" como o "nome fantasia” de um programa nacional de Segurança Pública. Há muito os programas públicos têm slogans formulados por marqueteiros, obedecendo às lógicas de fragmentação por nichos mercantis. 
ção de dinheiro, agora também relevante nas margens do social, a finalidade fundamental do repertório variável de regimes de governo da pobreza que recorta os pobres a partir da intensidade potencial do conflito que podem causar à ordem mercantil.

Para lançar essa perspectiva em debate, o artigo argumenta em três sessões que: 1) a representação da "violência urbana" retirou o centro irradiador da "questão social" contemporânea dos "trabalhadores", deslocando-o aos "marginais"; as políticas sociais afastaram-se do universalismo do direito social e, hoje, pensam a proteção social sobretudo tendo como pano de fundo a prevenção à violência; tornase plausível, então, a representação moral de um continuum entre os pobres, que tem, num polo, o "bandido" a encarcerar e, no outro, o "consumidor" ou o "empreendedor" a inserir via mercado; 2) nas práticas de governo, essa essencialização produz diferentes cortes no nível da população, objetivando distintas "vulnerabilidades sociais" e ensejando graus variados de "complexidade" da intervenção; 3) esse modo de governo seletivo - que associa técnicas tão díspares quanto transferência condicionada de renda e encarceramento, para não falar de extermínio - acabaria por favorecer, como efeito colateral, a emergência de um repertório de + regimes normativos nas periferias urbanas - esస tatal, do "crime" e religioso - todos regulando mercados monetarizados; é a monetarização, portanto, que passa a mediar centralmente a relação entre os grupos recortados, que, sob outras perspectivas mediadoras - a lei, a ordem, a moral - estariam em alteridade radical; o "desenvolvimento" centrado no consumo, portan$\therefore$ to, é alçado a forma de vida comum. Um traస̀ balhador não se confunde moralmente com um $>$ bandido, tampouco um policial tem a mesma posição frente à lei, se comparado a um traficante; ambos, entretanto, têm posições relativas muito próximas frente aos mercados de consumo. Como o dinheiro circula indiferenciadamente por mercados legais, ilegais ou ilícitos, a expansão mercantil conecta estes sujeitos e, por isso, também media os "acertos" entre eles, que fazem os mercados ilícitos e de mercadorias políticas (Misse, 2006a) crescerem. Assim, a mesma mão que fomenta a expansão do consumo da nova "Classe C" fomenta a violência urbana que pretensamente controlaria.

\section{A "QUESTÃO SOCIAL" NA ÓRBITA DA "SEGURANÇA PÚBLICA"}

Há um relativo consenso, na literatura, de que a questão social contemporânea incide sobre um deslocamento decisivo, operado desde as revoluções na França e nos Estados Unidos (Arendt, 1959, 1977), mas tornado visível sobretudo ao longo das últimas décadas, no centro da narrativa moderna que teve por norma a extensão universal da democracia (Rancière, 1995; Agamben, 1998). Na sociedade salarial, a questão social teria sido pautada pelo esforço de mediação pública e estatal dos efeitos desiguais da acumulação capitalista, centrados na extensão nacional dos direitos civis, políticos e sociais (Marshall, 1950) e compreendidos como a contrapartida universal do assalariamento (Donzelot, 1984; Silva, 1993; Rosanvallon, 1995). O "trabalhador" era a figura central a partir da qual se erigia o problema social e suas tentativas de solução. Ainda que essa contrapartida não se universalizasse de fato, o horizonte normativo (cognitivo e político) da resolução da "questão social" era formulado nos termos do bem estar social, dos limites à mercantilização das formas de vida, da internalização do conflito de classe nos modos de conceber e administrar o Estado e na produção de comunidades nacionais que visassem homogeneidade interna. A alteridade radical, que justificava inclusive as guerras, passou a ser figurada no estrangeiro. O Estado protege seus cidadãos da ameaça externa. ${ }^{7}$ Integração,

${ }^{7}$ Se a noção de questão social havia se notabilizado, sobretudo, no debate francês acerca do Estado de bem-estar (Ewald, 1986), o índice das contradições da modernidade política e econômica (Telles, 1999) nos levava a um horizonte crítico, ainda que paradoxal, na medida em que os problemas advindos da modernidade deveriam ser supera- 
inserção ou inclusão social, portanto, pautavam o problema social e os modos da intervenção estatal na pobreza de modo a produzir uma comunidade, ainda que remetessem a um redesenho evidente das tecnologias do poder (Foucault, 1976).

Castel (1999) demonstrou como essa equação foi desafiada nos países europeus, sobretudo na França, a partir dos anos 1980. Em novo cenário, caudatário da "reestruturação produtiva" e da "reforma neoliberal do Estado", instalava-se o desmanche, pela base, das mediações estatais que garantiam a efetivação de direitos, jogando para a defensiva a figura do "trabalhador formal", antes referência a atingir. A ascensão do "precariado", em sua informalidade, fazia do "desempregado estrutural" o signo da "vulnerabilidade" dos novos tempos. Se o cenário descrito por Castel, no final dos anos 1990, seguiu metamorfoseando-se até os dias de hoje, isso se deu, sem dúvida por radicalização do mesmo vetor de transformação da questão social por ele descrito. Os mercados informais e os postos de trabalho precário expandiram-se por todo o mundo, mesmo em cenários de desenvolvimento econômico e baixíssimo desemprego, como o brasileiro dos anos 2000. Mas também expandiram-se notavelmente nas economias centrais (Ruggiero \& South, 1997).

No Brasil, a regulação da cidadania (Santos, 1979) também apostou nessa chave e, no plano das práticas, mal chegou a lugares e pessoas marcados por sociabilidade, linguagem e códigos de conduta consideradas informais. Os classificados como pobres estariam imersos nas franjas da incompletude de processos estruturais da modernidade, daí a atribuição de "atraso" que permeia as leituras, do senso comum às universidades, acerca dos setores populares. As próprias noções de exclusão ou desfiliação, atestariam, assim, essa espécie de evolucionismo inscrito mesmo nessa formula-

dos nos marcos da própria teleologia moderna, pela criação e progressiva extensão dos direitos da cidadania. Cidadania seria, então, uma medida nas relações sociais (Telles, 1994). ção crítica da questão social.

O conflito social imanente às transformações recentes, que frustram esse ideal de cidadania, é mais radical que outrora, seja por vivenciarmos um momento de repactuação social ampla, seja porque - e essa é a hipótese central aqui - esse conflito não emana apenas, nem mais fundamentalmente, dos setores trabalhadores, integráveis pela narrativa da expansão dos mercados e dos direitos. Embora o trabalho e os direitos sigam exercendo papéis centrais no mundo das práticas sociais, o conflito social se situa hoje representado centralmente na expansão e progressiva tematização da "violência urbana", das "drogas" e da "marginalidade", ${ }^{8}$ que constroem sujeitos por definição não integráveis. Se a "luta por direitos do trabalhador", hegemônica nos anos 1980 e início dos 1990, lançava a questão social a um plano político (Paoli, 1995), a oposição central na qual parece situar-se o conflito social contemporâneo é, justamente, a clivagem moral que opõe a figura do trabalhador, compreendido então como um "homem de bem", partícipe da comunidade em seus anseios de progresso, daquela do "bandido" ou do "drogado", do "noia”, do "presidiário", enfim, do inimigo que, em sua simples existência, ameaça essa mesma comunidade. Nas diferentes figurações do outro a combater, o conflito inscrito na questão social se plasma agora em torno de uma ameaça essencial à ordem pública, subjetivada em corpos, territórios e palavras claramente definidos e internos aos territórios onde se vive. Não mais os inimigos estrangeiros: a ameaça vem de dentro, vem de perto, o inimigo é interno.

Já não se trataria, apenas, de admitir a "vulnerabilidade social" de moradores de rua, presidiários ou usuários de crack, para, em seguida, pautar sua necessária "reintegra${ }^{8}$ Não é, por exemplo, a estética do trabalhador aquela que dita, atualmente, os critérios de pertencimento das gerações jovens das periferias ao mundo social; expressões estéticas muitíssimo difundidas ali nas últimas décadas, como o rap ou o funk, demonstram uma partilha do sensível (Rancière, 1995) centrada em alteridade bastante mais radical que outrora (Bertelli, 2012; Feltran, 2013; Takahashi, 2013). 
ção” (Melo, 2014). Trata-se de equacionar essa "vulnerabilidade" ao potencial risco que eles representam. Como contrapartida, a depender da performance moral de cada sujeito ou grupo, oferecem-se doses (sempre tentativas, trata-se de um momento de transição) da mistura proteção social e controle, expandindo direitos e privações, atendimentos e disciplinarização, postos de saúde e criminalização, autoridade legítima e repressão violenta. ${ }^{9}$

Por isso, verifica-se a proliferação concomitante dos serviços sociais, sempre focalizados, e das estratégias de segurança pública e privada, vigilância e militarização dos territórios urbanos, igualmente focalizados. No Brasil, a expansão do acesso à casa própria pelo Programa Minha Casa Minha Vida, por isso, está em plena sintonia com a retomada dos deslocamentos forçados de indesejáveis urbanos, seja às periferias longínquas, seja a prisões, unidades e clínicas de internação, que incluem controle químico pela psiquiatrização. Oferece-se suporte para a "Nova Classe C" que expande mercados e preconiza-se seu isolamento das fatias populacionais que desarranjariam seu avanço. O problema aparece, apenas, quando se descobre que os empreendimentos em que a "Nova Classe C" vai viver estão situados em territórios nos quais não é se vislumbra que essa nova classe não está assim tão "segregada" do "crime", do PCC ou de suas dinâmicas, mas habita nos mesmos bairros. Quando se percebe que o outro a combater materializa-se, não poucas vezes, no próprio pai, irmão, marido, parente.

A grade de inteligibilidade do problema social se desloca, explicitamente, da questão social ao problema da violência, compreendido como problema associado entre criminali-

${ }^{9}$ A lógica vitoriosa dos governos de coalização desde a "transição democrática" brasileira no plano nacional, figurando como síntese a co-presença de Sarney e MST,

capital financeiro e economia solidária, ambientalistas e agronegócio, terceiro setor e evangélicos, por exemplo,

favorece o tipo de esquizofrenia - em sentido teórico - característico dessas ações șociais (mas também ambientais, políticas, econômicas). E sob esse signo que o governo contemporâneo parece ser melhor compreendido. dade, drogas e pobreza. Mas há descompasso entre essa grade e o próprio plano das práticas que ela pretenderia descrever, o que força as reclassificações, oriunda da desconfiança frente a estatutos previamente bem estabelecidos, como a própria cisão trabalhador versus bandido. Há muito mais tons de cinza entre eles quando se nota que o "mundo do crime" nas periferias também têm legitimidade para resguardar valores como paz, justiça, liberdade e igualdade; que gera renda e produz postos de trabalho e pertencimento, quando não novas famílias (Feltran, 2011; 2013). Publicamente, e sobretudo entre as elites, a reclassificação do mundo é muito mais lenta que nos cotidianos populares. Assim, na figuração pública trabalhadores e bandidos seguem sendo opostos pelo vértice, e a normativa política fundamental se desloca da integração dos trabalhadores à comunidade, em direção ao debate sobre segurança pessoal e patrimonial, calcada no controle de espaços e populações de risco, que produziriam as ameaças evidentes (usuários de drogas, marginais, ladrões, traficantes). Já não se trataria da extensão universal dos direitos da cidadania (não se oferecem direitos a inimigos), tampouco da validade universal das garantias democráticas (a exceção é tolerada, pode mesmo se tornar regra, quando se trata de "defender a sociedade"). A conflitividade social brasileira exige, portanto, recortes populacionais aos quais se vai dirigir um repertório de modos de governo, que variam hoje da democracia substantiva ao extermínio. Esse mosaico de modos de gerir os pobres é radicalmente distinto daquele ancorado no mito da democracia racial, da primeira metade do século XX, ou nas subsequentes tentativas de inserção social do trabalhador migrante nas cidades, integração regional ou extensão regulada dos direitos sociais aos excluídos. Nos últimos anos, o conflito social se expressa em cenário aparentemente contraditório: aumento das taxas da criminalidade acompanham aumento das taxas de emprego formal; políticas massivas de encarceramento são coetâneas à maior 
provisão de serviços sociais; megaoperações de requalificação urbana estão sintonizadas com a internação compulsória de usuários de crack; ocupação militar de territórios de favela acompanha consolidação de facções criminais.

Esse cenário paradoxal, portanto, associa o desenvolvimento econômico e a modernização de mercados à altíssima conflitividade social. Desagregar as populações em que cada um desses regimes atua é, portanto, fundamental.

No Brasil, traficantes, presidiários, moradores de rua e usuários de crack estão no centro da tematização pública do problema social contemporâneo - nas capas de jornais e revistas, em todos os meios. Não se pede que sejam tratados como cidadãos. Seu encarceramento, ou mesmo seu extermínio, são legitimados por parcelas consideradas incluídas e conectam-se diretamente, no plano dos debates públicos, à validação dominante das noções instrumentais de estado democrático e desenvolvimento. Diferentes trabalhos vêm demonstrando que bandidos, favelados, drogados e traficantes, pontos de gravitação do problema social brasileiro hoje, há muito já são figurados publicamente nos termos da alteridade radical (Misse, 2010; Grillo, 2013; Lyra, 2012; Biondi, 2010); a bibliografia internacional demonstra processos correlatos em diferentes países (Das; Poole, 2002; Jensen, 2008; Bourgois, 2012). Tendo os "inimigos" no seu centro, e desmoralizadas as narrativas de integração social universal, ou mesmo de luta política legítima em torno dos direitos comuns, o social passa a ser concebido como cerceado por um conflito irredutível, que o restringe e lhe reforça as fronteiras: há sempre um lado de dentro e um lado de fora da vida social, que portanto já não se confunde com vida nacional. Essa figuração choca-se com o centro da modernidade política inscrita na fórmula democrática. É em termos políticos, portanto, que a questão social mereceria ser recolocada: trata-se de uma redefinição do que é a vida da nação, da comunidade política.
É nos termos morais da representação da "violência urbana", entretanto, que ela tem sido difundida.

\section{A 'VIOLÊNCIA URBANA' E AS POLÍ- TICAS SOCIAIS ${ }^{10}$}

Luiz Antonio Machado da Silva já nos alertou, há duas décadas, para o erro de utilizar a noção de "violência urbana" como uma categoria de análise. Seria preciso, ao contrário, tomar essa representação como parte do problema a compreender, na medida em que é construção histórica e que constitui, em seu uso rotineiro, o que pretensamente descreve (Silva, 1993). Michel Misse já verificou a centralidade dessa afirmação para todo o campo de estudos sobre o crime e a violência, bem como os supostos que ela evidencia e os desdobramentos analíticos que ela propõe, válidos também para quem estuda as periferias (Misse, 2006a). Além disso, ensinou-nos que a primeira das "cinco teses equivocadas sobre criminalidade urbana no Brasil" é a de que "a pobreza é a causa da criminalidade, ou do aumento da violência urbana” (Misse, 2006b, 2010).

Para dialogar com essa produção com o mínimo de rigor, parece-me ser preciso, centralmente, evitar a reificação dos conceitos em pauta, que os figura como dados da "realidade". Não existe uma violência urbana em si mesma. A representação da "violência urbana" constitui-se fundamentalmente de um processo de associação arbitrária entre conceitos e fenômenos distintos, ao longo do tempo, que só comporiam um único fenômeno que, ao se reificar - por mecanismos diversos de objetivação - é apreendido como realidade e, por isso, se torna realidade. ${ }^{11} \mathrm{Em}$ nosso caso,

${ }^{10}$ Esta seção sintetiza e desenvolve argumentos já publicados, separadamente, em Feltran (2013a, 2014).

11 "Assim, nossas relações vão se desenvolvendo sobre a base de um saber mútuo, e esse saber sobre a base da relação real, como dois elementos indissociavelmente entrelaçados que, pela sua alternância dentro da interação, fazem com que essa apareça como um dos pontos em que o ser e a representação fazem empiricamente perceptível sua uni- 
nessa representação estão conectados fenômenos e conceitos tão díspares quanto criminalidade, drogas ilegais, mercados ilícitos, armas de fogo, facções, quadrilhas, corpos pardos e pretos, territórios urbanos e pobreza. Se o rigor analítico pede que cada um desses conceitos seja tratado considerando-se as distinções evidentes que carregam, nessa representação, ao contrário, eles são umbilicalmente indiferenciados. Cada um e a totalidade deles poderia, além do mais, significar uma faceta do nexo mais amplo, quando não tomado simplesmente como um sinônimo, da "violência urbana". As palavras chegam mesmo a se indiferenciar: em São Paulo, durante minha pesquisa de campo foram muitas as situações em que dizer "violência" era o mesmo que dizer "tráfico", "crime" ou "PCC" , bem como a ideia de que qualquer programa social que se dedique a um jovem favelado seria, evidentemente, de "prevenção à violência".

Não importa se as "drogas" atravessam as classes e se o "tráfico" é transnacional; nos significados da "violência urbana" ambos se corporificam em morros e favelas, numa cor de pele, numa idade, numa estética que pede para ser contida. Não importa se países como a Índia tenham imensa pobreza e taxas de homicídio muitíssimo mais baixas que países como os Esres do tráfico nas favelas estivessem desarmados durante os anos 2000, em São Paulo. O negócio do tráfico segue sendo representado como i algo tão violento que pôde equivaler legalmente a crimes hediondos, numa escalada de demanda por punição. Não importa, ainda, que o crii me dependa da lei que o tipifique, e seja sempre $\therefore$ muito mais amplo do que o conjunto de atos ลे que se utilizam de violência; o dispositivo da "violência urbana" faz com que "crime" seja reduzido ao ato violento, cometido por tão somente uma raça (aquela construída pela racialização dos pobres), definida agora com base na estética dos jovens das periferias. Não importa, tampouco, que as economias legal e ilegal sedade misteriosa” (Simmel, 2010, p.30-31). jam hoje interdependentes; crê-se, porque seria implausível pensar fora da chave bipolar legal versus ilegal contida nessa representação, que o crescimento econômico formal diminuiria os mercados globais da informalidade e da ilegalidade. Não é o que acontece em termos transnacionais, menos ainda o que aconteceu no Brasil, nas últimas décadas (Telles, 2011).

Se conceitos e fenômenos tão díspares aparecem nesse regime discursivo como naturalmente conectados, os sujeitos e espaços que materializariam esta conexão, conferindolhe concretude inquestionável, serão alçados a "típicos" da representação da "violência urbana”. Sua existência física seria a demonstração empírica de como todos os elementos arrolados efetivamente se combinam na prática. Sabotage, um rapper com muita melanina na pele e muita história na favela, cantou o que Michel Misse (2010) descreveu nos termos da sujeição criminal: "Já não sei qual que é/ Se me vêem, dão ré!". A figura do "noia", habitante das "cracolândias", é igualmente relevante para se notar como os dispositivos da "droga" (Fiore, 2012; 2014) e da violência se reificam em conexão. Mesmo sendo empiricamente uma parcela muito minoritária dos usuários da substância (Rui, 2012) aquela que faz dela um uso tão radical que chega ao ponto de viver nas ruas, ela é imediatamente acionada como imagem pública indelével ao se pronunciar a palavra crack. Toma-se a parte pelo todo, mas não por acaso: essa pequena parte permite, justamente, a naturalização imediata de todos os elementos nos quais a representação da violência se baseia - indignidade, sujeira, desordem, crime, violência, maldade, abjeção, imoralidade, risco, ameaça. Se a imensa maioria dos jovens de periferia não está "no crime", e se a imensa maioria dos que está no "crime" não comete crimes violentos, é, da mesma forma, essa minúscula parcela criminal e violenta a que representará toda a periferia quando se toma a "violência urbana" como grade de inteligibilidade.

Essa representação compõe, assim, uma fronteira cognitiva que define os limites até 
os quais os significados das palavras podem ser distendidos. No interior desse dispositivo a palavra "crime" não pode, por exemplo, ser esticada a ponto de se considerar que nele habitem sujeitos com fala e ação legítimas. Nesta representação, a lei define o crime como seu oposto e, como ela pressupõe-se como válida "para todos", em dado território, não é plausível pensar de outro modo. O fundo valorativo que acompanha a expressão "violência" é sempre negativo (Misse, 2006b). A representação da "violência urbana" opera, então, nos limites dos sentidos previamente determinados da apreensão de sujeitos e territórios que expressariam, nas suas essências, manifestas univocamente em suas ações, a violência que a significa. Não é plausível, no interior dessa representação, romper com essa valoração central que passa, então, a significar os conceitos do entorno, reificáveis a cada nova situação em que são mobilizados. A palavra "crime", entretanto, mesmo negativada na significação dominante pautada pela lei e ordem estatais, pode significar fonte de normatividade altamente positiva entre parcelas bastante relevantes da população brasileira (Hirata, 2010; Malvasi, 2012). Isso implica que se devem considerar esses enunciados nas situações potenciais de palavra, absolutamente dissensuais, em que aparecem usualmente. Dissenso que não remete apenas a argumentos, mas ao argumentável, ou seja, aos distintos parâmetros pelos quais se pode conceber o mundo.

A tematização pública da "violência urbana" representaria, assim, um modo ativo de produzir realidade e lhe ofertar conteúdos, o que, ao mesmo tempo, oculta aquilo que existe no mundo, formulado de modo alheio aos seus próprios termos. O que não é plausível nos termos desta representação só pode, portanto, ser considerado inexistente: o "mundo do crime" fazer homicídios diminuírem nas periferias de São Paulo, nos anos 2000, por exemplo. O que não se fala publicamente, entretanto, se comenta em privado. Entre os muito pobres, sobretudo, mas não apenas em São Paulo, o termo "cri- me" foi ganhando significados outros ao longo das últimas quatro décadas. A acumulação do conflito em torno do sentido dessas palavras fez do "crime", em situações determinadas das "periferias", um contraponto normativo e figurativo relevante à representação da "violência urbana". A função dessas duas representações me parece, hoje, centrada na tentativa de produzir cortes precisos na população, de modo a distribuir no tecido social um repertório de regimes governamentais diferentes a depender de "com quem se está falando".

A “nova geração de políticas sociais” já foi concebida sob a égide da "violência urbana". Atua recortando o social em diferentes grupos, que solicitam diferentes estratégias de intervenção. Em pesquisa de campo, a mesma travesti classificada como "trabalhadora do sexo" pelas políticas de saúde se tornou "moradora de rua" quando atendida pelo Centro de Referência Especializado para População em Situação de Rua - CREAS Pop, e "usuária de drogas" quando internada em uma clínica evangélica de recuperação (Martinez et. al., 2014). Suas "identidades", em cada caso, pediram doses muito distintas da equação assistência e repressão, que, no entanto, sempre estiveram presentes. Assim ocorreu em muitíssimos outros casos que temos estudado: os programas voltados aos marginalizados distribuem essa equação a partir de um continuum imagético que tem, num polo, a figura do "perigo" a ser francamente controlado e, no outro, a do novo consumidor ávido por mercados em expansão, seja pelo crédito, seja pelo aumento da renda; entre esses polos, há distintos níveis de "vulnerabilidades" que indicariam diferentes "complexidades" de casos (Breda, 2013), esquadrinhados pelos cadastros, reuniões de assistentes sociais, psicólogos, educadores, terapeutas ocupacionais, às vezes advogados (Matsushita, 2012). Em todos os casos, busca-se "encaminhar" o adolescente em conflito com a lei, a família "desestruturada", o viciado, o portador de necessidades especiais, o morador de rua, aquele que tem "distúrbios 
mentais”, e com maior ênfase os sabidamente potenciais criminosos, para outros programas de atendimento (encaminhamento profissional, proteção familiar, saúde, educação, atendimento psi, controle disciplinar, controle químico, internação). Quando eles escapam da chamada rede socioassistencial, e não é raro que o façam, esses mesmos indivíduos passam por unidades de contenção, prisões ou, mais raramente, mas não desprezivelmente, são assassinados. Estudos recentes com moradores de rua e jovens inscritos em mercados criminais demonstram que, mesmo com tantos recursos para atendimentos, ainda mata-se muito (Vianna \& Farias, 2011; Silva, 2014).

Matar, entretanto, é um último recurso. O argumento "contra a hipótese repressiva”, conhecido no domínio da sexualidade, parece também valer para muitas situações produzidas por aquilo que se poderia chamar, em linguagem foucaultiana, de dispositivo da "violência urbana”. ${ }^{12}$ Nunca os marginais, assim como o sexo, na modernidade, estiveram tão visíveis, nunca foram tão tematizados, nunca houve tantas políticas voltadas para eles. Armas de fogo, bandidos com o rosto coberto, policiais, drogas apreendidas e corpos estirados no chão povoam noticiários espetaculares e conversas de bar. Violência talvez seja o grande $\sharp$ tema da cinematografia nacional e internacio골 nal. Incitar a tematização da violência para, em seguida, classificá-la. Nunca se apostou tanto no encarceramento daqueles que se classificam como sendo seus artífices: homens jovens e pretos, pardos ou favelados, que levaram a sé-

i. 12 Michel Foucault (1997) argumenta que o dispositivo da $\curvearrowright$ sexualidade moderna não estaria centralmente preocupa¿ do em reprimir o sexo, de forma inespecífica; daí a profun são de discursos modernos que, ao contrário, o instigam స ainda hoje, das tardes de domingo às noites de sábado. $>$ Interessaria mais ao poder legitimar uma instância - sobe-

ث rana, disciplinar, governamental - a partir da qual se pudesse classificar legitimamente a sexualidade: descrevê-la categorizá-la, hierarquizá-la. A administração moderna do sexo se nutriria dessa operação de captura e reificação inscritas no ato de nomear, também ato de moralizar. O sig-

nificado dos nomes se rotinizaria como parte da natureza; normalizaria aquele sexo plausível de ser integrado à vida

familiar e produtiva, distinguindo-o daquele a ser banido da moral dominante, no limite da legalidade. Do quarto escuro dos pais de família aos mais abjetos puteiros, o dispositivo da sexualidade agiria classificando, para governar. rio a incitação orgiástica por consumo de carros, motos e mulheres, dinheiro fácil, cerveja e "vida loka". Tínhamos 45 mil presos no estado de São Paulo, em 1996; hoje, eles são mais de 200 mil. A chamada "população carcerária” segue crescendo, com metas precisas, e sua média etária ultrapassa pouco os 20 anos de idade. Se, acima, pensamos a prisão como a continuidade da assistência social, nessa chave, seria preciso inverter o raciocínio: aqueles que não merecem o encarceramento, e devem demonstrá-lo cotidianamente, é que podem aceder a programas sociais. A assistência parece ser, no plano cognitivo, a continuidade do controle, da contenção, da internação, da prisão.

O “outro" fundamental da ordem pública já não é o desempregado, que pede integração social por querer ser trabalhador, por ter índole e religião de trabalhador. Nosso outro agora é o "bandido", o inimigo público que precisa ser contido.

A guerra aparece mais e mais no léxico e na lógica das políticas estatais. Toda guerra, entretanto, enseja organização nos diferentes lados em conflito. Também dentro e fora da cadeia surgem instâncias administrativas e políticas como o Primeiro Comando da Capital e o governo capilar das igrejas evangélicas, outras instâncias de poder bastante presentes nos territórios em questão. As políticas estatais, aquelas produzidas pelo "crime" (Feltran, 2012; Silva, 2014) e por igrejas coexistem nas práticas, nos territórios, mas se querem autônomas uma frente às outras, no plano das representações (Machado, 2013; Vital, 2014; Fromm, 2013).

\section{CONFLITO, REGIMES NORMATIVOS E DINHEIRO}

Nos últimos anos, tenho trabalhado a hipótese - inspirada em Machado da Silva acerca da coexistência de regimes normativos distintos nas periferias de São Paulo, provisoriamente chamados de estatal, evangélico, criminal (Feltran, 2010, 2011, 2012; Silva, 2014; 
Fromm, 2013). São regimes que tentariam administrar a ordem das periferias urbanas, progressivamente autonomizando seus discursos frente aos concorrentes e, ao mesmo tempo, negociando mais acirradamente os consentimentos ativos, imposições, hibridizações e trocas entre eles no mundo das práticas. Regimes que irradiam discursos e orientam práticas desde locais muito específicos como igrejas evangélicas de diferentes denominações; pontos de venda de drogas, cadeias e mercados criminalizados; escritórios de postos de saúde, escolas, ONGs e entidades sociais, todos locais bastante relevantes nas periferias. Pastores, “irmãos” do PCC e funcionários públicos ritualizariam, em suas crenças e valores, a normatividade e dimensão de totalidade da lei de deus, dos códigos do "Partido" e do proceder, das funções administrativas e regulatórias estatais. Mas seus cotidianos e práticas se hibridizariam profundamente, produzindo sínteses pouco esperadas se olhadas pela perspectiva de cada normatividade. ${ }^{13}$ Pouco trabalhei, entretanto, sobre os modos internos de operação das moralidades em cada regime - o que implica em sensos de justiça e parâmetros de ação diferentes - e muito pouco pensei sobre as consequências do fato desses três regimes operarem mercados monetarizados, tentarem regulá-los, estimulando seu crescimento e nutrindo-se deles para sua própria expansão. Mercados legais, mercados criminais, mercados religiosos. Mercados que, se não se tocam na perspectiva moral ou legal, do ponto de vista monetário estão absolutamente conectados. A seguir, seguem algumas pistas nessa direção, seguramente ainda muito preliminares, abertas ao diálogo e a revisões constantes. Inicio pelos sensos morais e de justiça que parecem operar em cada um dos regimes apontados. Em

${ }^{13}$ Não apenas "ladrões evangélicos" ou "acertos entre policiais e criminosos", mas híbridos entre as normas religiosas e criminais, por exemplo (Marques, 2012). Hibridismos entre distintos regimes, nas práticas, são constantes nas periferias - sincretismo religioso, fusão de ideologias políticas etc. A Teologia da Libertação, associando materialismo histórico e cristianismo, por exemplo, foi extremamente bem sucedida por ao menos duas décadas no Brasil. seguida, procuro pelas relações que esses sensos de justiça produzem, com relação aos modos de circulação monetária que os conectam, sem produzir sínteses entre eles.

O regime estatal tem como mote a armadura legal republicana e mobiliza categorias como "lei", "ordem”, e seus correlatos "direito", "cidadania" e "democracia" como grandes mediadores normativos para o conflito social. Seus discursos seriam operados tanto por agências estatais por meio de instituições e políticas "públicas", quanto por ONGs e movimentos sociais, regulamentadas formalmente pelo legislativo, produzidas como ideal de justiça pelo judiciário e operadas idealmente por mercados assim regulados. As aspas se referem, sobretudo, à distância entre o que os princípios teóricos dessas noções indicam, e o que elas operam praticamente, sobretudo nas periferias urbanas. Nessa equação centrada na noção de "público", ou norteada por seus princípios universalistas, brotam, de um lado, programas de "segurança pública" como as UPPs, o Choque de Ordem, as Operações Saturação, todas as polícias civis e militares, bem como a ordem estatal, mais e mais militarizada, como Daniel Hirata (2010), Cibele Rizek (2013) lembram. Ordem que, de outro lado, oferece a chave de inteligibilidade para as "outras" políticas estatais de gestão do conflito social figurado nas periferias: programas focalizados de saúde, educação, profissionalização, moradia, cultura, esporte, as políticas urbanas mercantilizadas ou as miríades de "projetos sociais" que abundam nos territórios urbanos considerados tão pobres quanto violentos. Entidades tão distintas quanto escolas e postos de saúde, sindicatos e ONGs, centros culturais, de lazer e esporte, quando voltados para atender os pobres, passam a justificar suas ações como de "prevenção à violência". A representação de que, sem esses programas, meninos das periferias estariam prestes a agir violentamente contra outros setores sociais justifica, de modo notável, a premência e a relevância das sempre novas formas de "ação social" nas periferias. O Pronasci tem frentes 
repressiva e assistencial associadas, a UPP tem como correlata a UPP Social, a segurança tem como contrapartida os "direitos sociais”, não o oposto. Essa equação, evidentemente, faz questão de desconhecer, para deslegitimar, formas outras de organização familiar, comunitária, social ou política, criadas nos cotidianos dos próprios pobres, muitas delas com longa tradição, que, no entanto, seguem existindo e balizando práticas e valores compartilhados por muitos.

Os debates agonísticos face a face, muito presentes em todos os setores sociais, mas que gozam de legitimidade desproporcionalmente superior no mundo popular, respondem à lógica moral muito distinta daquela do direito legal, sobretudo por não serem pautados por regras formais ou por instituições pretensamente legítimas por definição. A dimensão narrativa - contar o que houve - é muito mais presente neles do que a dinâmica conceitual da legislação formal. Julga-se em conjunto sobre algo que aconteceu, a partir de narrativas performadas pelos interlocutores. São debates pautados por valores morais, portanto, quase sempre inspirados na religiosidade cristã "velho-testamentista" (olho por olho, dente por dente). Nesses inúmeros debates cotidianos em torno da definição do que é o certo nas periferias e códigos pré-estabelecidos mas valores compartilhados. Valores que quase nunca são definidos abstratamente a priori, mas que são significados durante e após as performances cotidianas, individuais e coletivas, permitindo que se delibere pela justeza das condutas e reputação dos sujeitos. Valores que fundam comunidades, e imaculáveis em princípio, como "respeito", "humildade" e "igualdade" não são abstrações ou princípios gerais, mas ao contrário, são percebidos como sendo (ou não) concretizados cotidianamente em atos comentados, fofocados, avaliados (Marques, 2010).

O conjunto de atitudes reconhecidas recorrentemente pelos pares como direcionadas para o “certo”, em São Paulo, dá sentido prático a palavras como "proceder", "procedimento" ou "correr pelo certo", que ensejam a subjetivação de homens e mulheres "considerados", "respeitados", "cabulosos" e "humildes" simultaneamente, em espaços sociais específicos. Adalton Marques (2010) e Karina Biondi (2014) foram, talvez, os pesquisadores que melhor estudaram esse senso compartilhado de justiça, muito explicitamente louvado no "mundo do crime" paulista, que têm por intenção final não apenas evitar os desfechos violentos, no limite à espreita, mas também propor um universo social no qual esses valores, nunca reificáveis absolutamente, fossem as balizas para uma vida comum. Ousaria dizer que é nesse modo, não republicano e inteiramente performático, não estatal (e mesmo "contra o Estado”, com Pierre Clastres) e que opera por princípios postos a prova a cada situação (Cefai), que indivíduos conhecidos como "crentes" e "trabalhadores" das periferias, mas também como "ladrões" e "bandidos", definem em suas vidas o que é "certo" na resolução de seus conflitos; esse modo de resolução pode ser mais ou menos institucionalizado, sacralizado ou ritualizado, e seguramente tem como pano de fundo o universo cristão (Takahashi, 2013). Percebe-se, assim, por que é que a religiosidade evangélica e pentecostal, e mesmo a moralidade estrita do "crime" podem ser tão mais pervasivos, e expandirem-se tanto mais do que a "lei e a ordem" estatais nos universos periféricos. Trata-se da disputa entre gramáticas morais legítimas localmente, contrapostas a idiomas estatais concebidos, majoritariamente, como exógenos, elitistas ou mesmo equivocados moralmente. Wittgenstein, nas Investigações Filosóficas, pensa o sentido como produzido apenas no uso situacional das palavras, não como contido em sua semântica. Os sentidos do "certo", do "justo" e do "belo" nas periferias são, sem dúvida, afeitos a essa interpretação.

Mas os regimes normativos citados estatal, evangélico, do "crime" - não atuam apenas na dimensão moral ou administrativa 
dos territórios estudados, produzindo códigos de conduta e sensos de justiça. Todos eles operam também mercados monetarizados que também mediam relações de conflito potencial, muitas vezes muito fortes, como aqueles entre policiais e "traficantes" que, como não encontram na lei ou nas moralidades modos de mediar suas interações necessárias, encontram no dinheiro um modo objetivo de dirimir suas diferenças: os pagamentos de "acertos" (ou "arregos", como se diz no Rio de Janeiro), que variam de valor e são negociados de formas distintas entre policiais e operadores de mercados ilegais. Misse (2006a) já demonstrou como a circulação das mercadorias políticas, como essa, modula as sempre tensas relações entre a ordem legal e a operação cotidiana, funcional a essa mesma ordem, dos mercados informais, ilegais e ilícitos. Grillo (2013), Hirata (2010), Silva (2012) demonstram que sua interpretação é perfeitamente aplicável a outros contextos.

As periferias urbanas brasileiras foram fundamentais à acumulação mercantil e aos "livres mercados", direta ou indiretamente, seja nas perspectivas de Kowarick (1975) ou Oliveira (1982), que notam agudamente a extração de sobrevalor na própria forma de urbanização, seja mais recentemente na instalação profícua das formas mais flexíveis de acumulação capitalista de fronteira (os mercados ilícitos como o narcotráfico, o contrabando e o roubo de carro, altamente lucrativos dada a muito menor mediação institucional). Os trabalhos de Galdeano (2013) e Côrtes (2013) indicam como a lógica empreendedora atravessa "evangélicos", "bandidos" e atores estatais, transformando todos eles também em operadores de mercados, dos mais diversos. A segurança privada, na rua Conde de Sarzedas em São Paulo, mas também os cultos midiáticos descritos por Birman (2012) e Machado (2012) sustentam-se em formas mercantis. A habitação social contemporânea é a ponta da operação de mercados financeiros transnacionais (Shimbo, 2013). Os garotos armados estudados por Lyra
(2013) trabalham para o tráfico transnacional. Assim também os policiais da base da corporação ou os agentes prisionais, quando negociam com seus "desafetos" nas biqueiras e cadeias, fazem dinheiro circular em diferentes escalas e situações das mais às menos legítimas (Hirata, 2010, 2011, 2013). A expansão do consumo popular, estimulada centralmente, radicaliza a objetivação de inúmeros conflitos sociais. Reduzir os fenômenos tratados ao economicismo analítico seria desconhecer a crítica da qual partimos, muitos dos autores com os quais dialogo aqui, para pensar as margens da cidade. Não reconhecer as formas evidentes de monetarização aqui presentes, inclusive como regulação dos conflitos entre diferentes regimes normativos, seria talvez ainda mais grave. Miagusko (2013) demonstra a escalada de violência letal que se dá, numa favela carioca, quando um traficante decide, unilateralmente, que deixaria de pagar os "arregos" a policiais. Sem o dinheiro na mediação desse conflito, ele se torna muito mais letal. Sem pagamento de salários, um conflito trabalhista se torna gravíssimo. Muitos trabalhadores da droga, revendedores de contrabando, donos de desmanche, pastores e "irmãos" do PCC são, também, empresários; todos os que se relacionam com eles, cotidianamente, alimentam pelo trabalho e pelo consumo a circulação de moeda, em franca expansão nas periferias brasileiras. A ampliação da renda popular, do salário mínimo, do crédito e dos programas de transferência de renda são parte do desenvolvimento, também, de mercados ilegais, informais e ilícitos.

Essas três equações de mediação de potenciais conflitos - a lei, o certo, o dinheiro - que em última instância administrariam a violência e produziriam ordem, nem sempre conseguem fazê-lo. O social tem sido marcado por alteridade cada vez mais radical, porque a lógica que garantiria a expressão política da pluralidade social é cada vez mais minoritária. Cindido entre regimes normativos cada vez mais autônomos, o conflito que hoje interessa perscrutar não é o conflito de opiniões elaboradas a 
partir de um mesmo pano de fundo epistêmico, um mesmo regime normativo, uma mesma comunidade. A grade de inteligibilidade da guerra entre grupos recortados da população, que já não compõem uma única comunidade moral ou legal, mas apenas uma comunidade mercantil, parece fazer cada vez mais sentido para compreender os conflitos contemporâneos. Quando nem a lei, nem o que é considerado certo podem mediar a relação entre cortes populacionais e seus modos progressivamente autônomos de conceberem a si e aos outros, é o dinheiro que aparece como único modo objetivo de mediar suas relações. Ao invés de politizar a questão social ou os pilares da vida comunitária, portanto, parece-me que o híbrido dessas equações de mediação - o dinheiro - tem, ao contrário, elevado em muito a intensidade do conflito latente entre as formas de vida que, hoje, se elaboram nos cortes biopolíticos que esquadrinham as cidades brasileiras. Valores, costumes e crenças comuns não se apresentam mais como fundamento de coesão de grupos sociais; o dinheiro parece ser a aposta para ocupar esse lugar. Dinheiro suficiente para a mediação entre esses recortes pode inibir as manifestações violentas do conflito que os cinde, segrega, separa. Um momento de crise econômica nos faria ver a violência de sua t expressão não mediada. 'questão social', no Brasil contemporâneo, deslocou-se da integração dos pobres por um projeto de desenvolvimento nacional que se faria pela expansão dos mercados de trabalho e da cidadania', para outra chave, a da gestão i do conflito social e urbano, que agora seria \& causado pelos pobres, pela monetarização das ลे relações sociais entre grupos progressivamente distintos. Cabem no projeto de nação aqueles que são funcionais ao mercado monetarizado. O diagnóstico do nosso problema social, portanto, mudou tão radicalmente que as políticas voltadas para saná-lo tiveram seu sentido invertido. Se há duas ou três décadas pôde-se pensar o conflito social como fundamental- mente causado por desigualdade e ditadura, a serem superadas estruturalmente, hoje trata-se de fomentar o mercado que desenvolveria o país e controlar a violência que emergeria dos pobres e cria obstáculos ao "nosso" progresso material. As políticas sociais, os discursos públicos acerca da pobreza e seus territórios, as estratégias de gestão estatal, não governamental e religiosa do conflito social pautamse agora pela lógica instrumental da eficiência mercantil, do custo-benefício, em tendência de objetivação agressiva das relações sociais. Colocar milhares de presos para trabalhar quase de graça, dentro das cadeias, é considerado um "programa social" de ponta, pelos governos e empresários. Todos saem lucrando. Gerir o social é, portanto e fundamentalmente, expandir os mercados. O cartão do Bolsa-Família é paradigmático - as políticas sociais do futuro fomentam a inclusão mercantil.

Constata-se, no entanto, que se o mercado das drogas alavanca a economia, viciados em estágio avançado, vagabundos e moradores de rua se beneficiam dele, mas não se "integram". Alguns são ainda piores: mesmo operando mercados altamente lucrativos, não se conformam com seus lugares e se tornam "violentos" (traficantes, ladrões, membros de facções criminais). É, portanto, fundamental associar ao dispositivo mercantil uma cunha de destituição do "direito a ter direitos", operada pela incriminação seletiva, que encontra altíssima legitimidade social. Expandir os mercados e incriminar os sujeitos que criam problemas - sem nunca reprimir a circulação de valor pelos mercados que eles operam - compõem, portanto, faces da mesma moeda. O tráfico de drogas ou o roubo de carros, por exemplo, não são reprimidos em suas dimensões de negócio, em seus mercados. A repressão se faz aos pequenos traficantes ou ladrões que, quando incriminados seletivamente e colocados em unidades de internação ou prisões, cedem seus postos de trabalho para que outros, como eles, façam o mesmo mercado e a mesma lógica de controle social seguirem operando. 
Daí a emergência das duas figurações contemporâneas da pobreza - a do consumidor a integrar e a do bandido a encarcerar. Ambas compõem um mesmo dispositivo que produz e tenta remediar - a "questão social" contemporânea. Antes de tomar esse mundo social como dado, parece-me imperativo refletir sobre os pressupostos cognitivos que o produzem. Que distorções neste mundo seria preciso conceber para que um cidadão de 15 anos, funcionário de uma micro-empresa varejista de São Paulo, possa ser chamado de trabalhador quando passa madrugadas revendendo, sem garantias trabalhistas ou proteção das organizações contrárias ao trabalho infantil, cocaína para quem quer comprar? Que deslocamento cognitivo seria preciso realizar para que seus modos de conceber o mundo sejam considerados aptos a serem enunciados e ouvidos publicamente, sem que isso represente defesa de bandido? Parece-me que é a esse deslocamento no modo de pensar o social, empiricamente cada vez mais longínquo pela tendência de objetivação monetarizada do laço entre pessoas e grupos, que o trabalho intelectual - um dos poucos que ainda resiste à mediação monetária - poderia contribuir.

Recebido para publicação em 08 de julho de 2014 Aceito em 15 de agosto de 2014

\section{REFERÊNCIAS}

ADORNO, Sérgio; SALLA, Fernando. Criminalidade organizada nas prisões e os ataques do PCC. Estudos avançados: dossiê crime organizado, São Paulo, v. 21, n. 61, p. 7-29, dez. 2007.

AGAMBEN, Giorgio. Homo Sacer: sovereign power and bare life. Stanford: Stanford University Press, 1998.

ARENDT, Hannah. The human condition: a study of central dillemas facing modern man. New York: Doubleday Anchor Book, 1959.

. On revolution. New York, Penguin, 1977.

. A crise na cultura: sua significação social e política. In: Entre o passado e o futuro, São Paulo: Perspectiva, 2001.

ARRETCHE, M. Federalismo e igualdade territorial: uma contradição em termos? Dados, Rio de Janeiro, v. 53, p. 587-620, 2010.

- Classe média, desigualdade e eleições. Valor Econômico, São Paulo, p. 6, 06 fev. 2014.

BIRMAN, Patrícia; MACHADO, Carly. A violência dos justos: evangélicos, mídia e periferias da metrópole. Revista Brasileira de Ciências Sociais. v. 27, n. 80, out 2012.

BREDA, Roselene. Entre recursos e escolhas: limites e possibilidades em torno das rotinas de atendimento de um CRAS. 2013. 64f. Monografia de conclusão de curso (Sociologia). Departamento de Sociologia da Universidade Federal de São Carlos, 2013.

CABANES, Robert (Org.); GEORGES, Isabel (Org.); RIZEK, Cibele S. (Org.); TELLES, Vera da Silva (Org.). Saídas de Emergência - ganhar/perder a vida na periferia de São Paulo. 1. ed. São Paulo: Boitempo Editorial, 2011. v. 1. 478p .

CALDEIRA, Teresa Pires do Rio. Cidade de muros: crime, segregação e cidadania em São Paulo. São Paulo: Edusp, 2000.

CASTEL, Robert. Les métamorphoses de la question sociale: une chronique du salariat. Paris: Gallimard, 1999. (Collection Folio Essais; n. 349)

CAVELL, Stanley. Foreword. In: DAS, Veena. Life and words: violence and the descent into the ordinary. California: University of California Press, 2006

CUNHA, Neiva Vieira da; FELTRAN, Gabriel de Santis. Sobre periferias: novos conflitos no Brasil contemporâneo. Rio de Janeiro: Lamparina, 2013.

DAGNINO, Evelina. Citizenship: a perverse confluence. Development in Practice, Oxford, v. 17, n. 4/5, p. 549-556, 2007.

Sociedade civil, espaços públicos e a construção democrática no Brasil: limites e possibilidades In: DAGNINO, Evelina. (Org.) Sociedade civil e espaços públicos no Brasil. São Paulo: Paz e Terra, 2002.

Os movimentos sociais e a emergência de uma nova noção de cidadania. In: DAGNINO, Evelina (Org.). Os Anos 90: política e sociedade no Brasil, São Paulo: Brasiliense, 1994.

DAS, Veena; POOLE, Deborah. El Estado y sus márgenes: etnografías comparadas. Buenos Aires: Paidós, 2002.

. Entre palavras e vidas: um pensamento de encontro com margens, violências e sofrimentos: entrevista a Michel Misse, Alexandre Werneck, Patrícia Birman, Pedro Paulo Pereira, Gabriel Feltran e Paulo Malvasi. Revista Dilemas, Rio de Janeiro, v.2, n. 5, abr./jun. 2012.

DONZELOT. Jacques. Linvention du social: essai sur le déclin des passions politiques. Paris, Fayard, 1984. (Collection. L'Espace du politique).

DURHAM, Eunice Ribeiro. A dinâmica da cultura. São Paulo: Cosac Naify, 2005.

EWALD, François. L'État providence. Paris, Grasset, 1986. FELTRAN, Gabriel de Santis. Crime e periferia. In: LIMA, Renato Sérgio de; RATTON, José Luiz; AZEVEDO, Rodrigo Ghiringhelli de (Org.). Crime, polícia e justiça no Brasil. São Paulo: Contexto, v. 1, p. 299-307, 2014.

Questão social e lumpen. In: IVO, Anete Brito Leal (Coord.) et. al. Dicionário temático desenvolvimento e questão social. São Paulo; Brasília; Salvador: Annablume; CNPq; FAPESB, v. 1, p. 400-404, 2013.

Governo que produz crime, crime que produz governo. O dispositivo de gestão do homicídio em São Paulo (1992-2011). Revista Brasileira de Segurança Pública, v. 6, p. 232-255, 2012.

Fronteiras de tensão: política e violência nas periferias de São Paulo. São Paulo: Editora da Unesp/CEM, 2011.

Periferias, direito e diferença: notas de uma etnografia urbana. Revista de Antropologia, São Paulo, v. 
53, n. 2, n. esp. Antropologia do Direito, p. 565-610 jul./ dez. 2010.

A fronteira do direito: política e violência nas periferias de São Paulo. In: DAGNINO, Evelina; TATAGIBA, Luciana (Orgs.). Democracia, sociedade civil e participação. Chapecó: Unochapecó, 2007.

FIORE, Maurício. Uso de drogas: substâncias, sujeitos e eventos. Tese de Doutorado (Antropologia), Campinas: Universidade Estadual de Campinas, 2013.

. O lugar do estado na questão das drogas: o paradigma proibicionista e as alternativas. Novos Estudos CEBRAP, São Paulo, v. 92, p. 9-21, mar. 2012.

FOUCAULT, Michael. Histoire de la sexualité 1: La volonté de savoir. Paris: Gallimard, 1976.

FROMM, Deborah. Deus e o diabo na terra do crack. 2014. 55f. Monografia de conclusão de curso (Ciências Sociais) Departamento de Sociologia da Universidade Federal de São Carlos, 2014

GEORGES, Isabel. Trabalho informal e representação sindical. In: RIZEK Cibele Saliba (Org.). Saídas de emergência: ganhar/ perder a vida na periferia de São Paulo. São Paulo: Boitempo, (Coleção Estado de Sítio). p. 135-152. 2011.

GRILLO, Carolina Christoph. Coisas da vida no crime: tráfico e roubo em favelas cariocas. 2013. $280 \mathrm{f}$. Tese (Doutorado em Ciências Humanas). Programa de PósGraduação em Sociologia e Antropologia do Instituto de Filosofia e Ciências Sociais da Universidade Federal do Rio de Janeiro, 2013.

GUIMARÃES, Antonio Sergio Alfredo. The Brazilian system of racial classification. Ethnic and Racial Studie (Print), v. 35, p. 1157-1162, 2012a.

GUIMARÃES, Nadya Araujo. À procura de trabalho: instituições do mercado e redes. Belo Horizonte: Fino traço, 2009. (Coleção Trabalho \& Desigualdade). 221p.

A procura de trabalho: uma boa janela para mirarmos as transformacões recentes no mercado de trabalho? Novos Estudos CEBRAP, São Paulo, v. 93, p. 123144, jul. 2012.

HIRATA, Daniel. São Paulo: cidade securitária e novo mercados. In: VELOSO, Sérgio; ABDENUR, Adriana Erthal; ESTEVES, Paulo. (Org.). As Cidades e os BRICS. $1^{\mathrm{a}}$ ed. Rio de Janeiro: Editora PUC Rio, p. 179-196, 2013.

KOWARICK, Lúcio. A espoliação urbana. Rio de Janeiro: \& Paz e Terra, 1975.

novos . MARQUES, Eduardo Cesar Leão. São Paulo: Paulo: Editora 34, v. 1. 398p, 2011.

(ै)

MACHADO, Carly 'É muita mistura': projetos religiosos, จ políticos, sociais, midiáticos, de saúde e segurança pública is nas periferias do Rio de Janeiro. Religião e Sociedade, v. เo 33, p. 13-36, 2013.

. Violência urbana: representação de uma ordem 2. social. In: NASCIMENTO, E. P; BARREIRA, Irlys. (Orgs.)

Brasil urbano: cenários da ordem e da desordem. Rio de ¿. Janeiro: Notrya, 1993.

今 MALVASI, P. Interfaces da vida loka: um estudo sobre jovens, tráfico de drogas e violência em São Paulo. Tese $>$ de Doutorado (Saúde Pública), São Paulo: Universidade de São Paulo, 2012.

MARQUES, Eduardo Cesar Leão. Governo e governança em grandes cidades: Paris, Londres, Cidade do México e São Paulo. Projeto de Pesquisa (mimeo). Financiamentos: CNPq, CAPES, FAPESP, 2014.

Opportunities and deprivation in the urban south: poverty, segregation and social networks in São Paulo. 1. ed. Farnhnam: Ashgate Publishers, v. 1. 186p. 2012.
Redes sociais, segregação e pobreza. São Paulo: Unesp, v. 1. 215p. 2010.

.; BICHIR, Renata. Redes de apoio social no Rio de Janeiro e em São Paulo. Novos Estudos CEBRAP, São Paulo, n. 90 , p. $10-32$, jul. 2011

MARSHALL, Tomas Humphrey. Citizenship and social class. Cambridge: Cambridge University Press, 1950.

MARTINEZ, Mariana Medina; OLIVEIRA, Luciano Márcio Freitas de; PEREIRA, Luiz Fernando de Paula; PAZZINI, Domila do Prado; BARBOSA Aline Ramos. A produção e a gestão da população de rua: a trajetória de Luciene. Dilemas (Revista de Estudos de Conflito e Controle Social), v. 7 , n. 4 , p. 741-767, 2014

MATSUSHITA, Leilane Latorre. Perspectivas do caso Beth. 2012. 57p. Monografia de Conclusão de Curso (Ciências Sociais), Universidade Federal de São Carlos, 2012.

MELO, Felipe Athayde Lins de. As prisões de São Paulo: Estado e mundo do crime na gestão da "reintegração social”. Sâo Paulo: Alameda, 238p., 2014.

MISSE, Michel. Crime, sujeito e sujeição criminal: aspectos de uma contribuição analítica sobre a categoria 'bandido'. Lua Nova Revista de Cultura e Política. São Paulo, n. 79, p. 15-38, 2010.

Sobre uma sociabilidade violenta. In: MISSE, Michel. Crime e violência no Brasil contemporâneo: estudos de sociologia do crime e da violência urbana. Rio de Janeiro, Lumen Juris, 2006a.

Cinco teses equivocadas sobre a criminalidade violenta no Brasil. In: MISSE, Michel. Crime e violência no Brasil contemporâneo: estudos de sociologia do crime e da violência urbana. Rio de Janeiro, Lumen Juris, 2006b.

O Rio como um bazar: a conversão da ilegalidade em mercadoria política. Em: MISSE, Michel. Crime e violência no Brasil contemporâneo: estudos de sociologia do crime e da violência urbana. Rio de Janeiro, Lumen Juris, 2006c

OLIVEIRA, Francisco de. (Org.); RIZEK, Cibele. S. (Org.) $A$ era da indeterminação. 1. ed. São Paulo: Boitempo Editorial, v. 1. 376p. 2007.

O espaço e o urbano no Brasil. Espaço e Debates, São Paulo, n. 6, 1982

PAOLI, Maria Celia Pinheiro Machado. Movimentos sociais no Brasil: em busca de um estatuto político. In: HELLMANN, Michaela (Org.) Movimentos sociais e democracia no Brasil. São Paulo: Marco Zero, 1995.

RANCIÈRE, Jacques. La mésentente: politique et philosophie. Paris: Galilée. 1995. (Collection La philosophie en effet)

$O$ mestre ignorante: cinco lições sobre a emancipação intelectual. Belo Horizonte: Autêntica, 2002. ROSANVALLON, Pierre. La nouvelle question sociale: repenser l'Etat-providence, Paris, Seuil, 1995.

RUI, Taniele Cristina. Corpos abjetos: etnografia em cenários de uso e comércio de crack. 2012. 235f. Tese (Doutorado em Antropologia), Instituto de Filosofia e Ciências Humanas, Universidade Estadual de Campinas Campinas, SP, 2012.

RUGGIERO, Vincenzo.; SOUTH Nigel. The late city as a bazaar: drug markets, illegal enterprise and the barricades. The British Journal of Sociology, London, v. 48, n. 1, p. 5470, marc. 1997

SADER, Eder. Quando novos personagens entraram em cena: Experiências, Falas e Lutas dos Trabalhadores da Grande São Paulo, 1970-80. Rio de Janeiro: Paz e Terra, 1988.

SANTOS, Wanderley Guilherme dos. Cidadania e justiça: 
a política social na ordem brasileira. Rio de Janeiro, Ed. Campus, 1979

SILVA, Carlos Freire da. Mercado informal e Estado: jogos de poder entre tolerância e repressão. In: AZAIS Christian, KESSLER, Gabriel, TELLES, Vera da Silva. Ilegalismos, cidade e política. Belo Horizonte: Fino Traço, 2012. (Coleção Sociedade e cultura; 11)

SILVA, José Douglas dos Santos. Se o irmão falou, meu irmão, é melhor não duvidar: políticas estatais e políticas do "crime" em relação a homicídios em São Paulo. Dissertação (Mestrado em Sociologia), Universidade Federal de São Carlos, 2014.

SILVA, Luiz Antonio Machado da. Sociabilidade violenta: por uma interpretação da criminalidade contemporânea no Brasil urbano. Sociedade e Estado, Brasília, v. 19, n. $1,2004$.

Violência urbana: representação de uma ordem social. In: NASCIMENTO, Elimar Pinheiro; BARREIRA, Irlys. (Orgs.) Brasil urbano: cenários da ordem e da Irlys. (Orgs.) Brasil urbano: cenários
desordem. Rio de Janeiro: Notrya, 1993.

SIMMEL, Georg. Philosophy of money. London: Routledge, 1990 [1900].

O conceito e a tragédia da cultura. Crítica Cultural. Palhoça, SC, v. 9, n. 1, p. 145-162, jan./jun. 2014.

El secreto y las sociedades secretas. Madrid: Sequitur, 2010.

TAKAHASHI, Henrique Yagui. Evangelho segundo Racionais MC's: ressignificações religiosas, políticas e estético-musicais nas narrativas do rap. 2014, 173f. Dissertação (Mestrado em Programa de Pós-Graduacão em Sociologia), Universidade Federal de São Carlos. São Paulo. 2014
TELLES, Vera da Silva. A cidade nas fronteiras do legal e ilegal. São Paulo: Argvmentvm/USP, 2010. (Coleção Sociedade \& Cultura).

Pobreza e Cidadania. São Paulo: Editora 34, 2001.

Trajetórias urbanas: fios de uma descrição da cidade. In: TELLES, Vera da Silva, CABANES, Robert. (orgs.) Nas tramas da cidade: trajetórias urbanas e seus territórios. São Paulo: Associação Editorial Humanitas, IRD, 2006.

Sociedade civil e a construção de espaços públicos. In: DAGNINO, Evelina (Org.) Anos 90: política e sociedade no Brasil. São Paulo: Brasiliense, 1994.

; CABANES, Robert. (Orgs.). Nas tramas da cidade trajetórias urbanas e seus territórios. São Paulo: Associação Editorial Humanitas, IRD, 2006.

.; HIRATA, Daniel Veloso. Cidades e práticas urbanas: nas fronteiras incertas entre o ilegal, o informal e o ilícito. Estudos Avançados, Dossiê Crime Organizado, São Paulo, v. 21, n. 61, p. 173-191, dez. 2007.

; PAOLI, M. C. Direitos sociais: conflitos e negociações no Brasil contemporâneo. In: ALVARES S.E.; DAGNINO, Evelina; ESCOBAR, A. (Org.). Cultura e política nos movimentos sociais latino-americanos. Belo Horizonte: Editoria UFMG, 2000, p. 103-148.

VIANNA, Adriana R. B.; FARIAS, Juliana. A guerra das mães: dor e política em situações de violência institucional. Cadernos Pagu, Campinas, v. 37, p. 79-116, dez. 2011.

ZALUAR, Alba M. Integração perversa: pobreza e tráfico de drogas. 1. ed. Rio de Janeiro: Fundação Getúlio Vargas, v. 1. 440 p. 2004 
THE VALUE OF THE POOR: the gamble that cash money can mediate contemporary social conflict

\author{
Gabriel de Santis Feltran
}

In contemporary Brazil, the urban periphery have two recent and dichotomous figurations: the cause of "urban violence" that calls for more repression and the core of the "development" which can turn poor people into "middle class". This essay argues that the representation of "urban violence" displaced the center of contemporary "social question" from "the worker" to the "marginal people". The collapse of universalism involved in this shift entails a selective government that categorizes the population in varying degrees of "vulnerability" and levels of "complexity" of state intervention; as a side effect, different regulatory regimes emerge on urban peripheries - e.g., state, "crime" and the religious - that although always in tension, have cognitive cohesion based in monetized markets. The money seems to mediate the relationship between forms of life which, from other perspectives - legal or moral - would be in radical alterity; consumption emerges as a form of common life and mercantile expansion, above all, connects legal and illegal markets, including fostering urban violence that development allegedly would control.

KEY wORDS: Urban outskirts. Violence. Development. Money. Value

Gabriel de Santis Feltran - Doutor em Ciências Sociais. Professor do Departamento de Sociologia da Universidade Federal de São Carlos (UFSCar). Pesquisador do Centro de Estudos da Metrópole (CEM) e do Núcleo de Etnografias Urbanas do Centro Brasileiro de Análise e Planejamento (CEBRAP). Atualmente pesquisa as dinâmicas sociais e políticas das periferias urbanas, com foco nos grupos marginalizados e no "mundo do crime" em São Paulo. Coordenador do NaMargem - Núcleo de Pesquisas Urbanas e do Projeto As margens da cidade, que integra o CEPID/CEM - FAPESP. Publicações recentes: Sobre anjos e irmãos: cinquenta anos de expressão política do -crime- numa tradição musical das periferias. Revista do Instituto de Estudos Brasileiros, v. 1, p. 43-72, 2013; Entre palavras e vidas: um pensamento de encontro com margens, violências e sofrimentos. Entrevista com Veena Das. Dilemas: Revista de Estudos de Conflito e Controle Social, v. 5, p. 335-356, 2012; Governo que produz crime, crime que produz governo: o dispositivo de gestão do homicídio em São Paulo (1992-2011). Revista Brasileira de Segurança Pública, v. 6, p. 232$255,2012$.

\section{LA VALEUR DES PAUVRES - Parier que l'argent contemporain}

Au Brésil, les banlieues sont au centre de deux types de représentations récentes et dichotomiques: violence urbaine" qu'appelle a davantage nouvelles "classes moyennes". Cet article soutient que la representation de la violence urbaine a conduit à un déplacement du foyer de la "question sociale" contemporaine de l'ancienne figure du ur" vers celle du "marginal". L'effondrement s'accompagne d'un mode de gouvernement découpan la population de manière sélective en fonction de divers coefficients de "vulnérabilité". Corollaires de ces évolutions, de nouveaux régimes normatifs cer dans les "periferias", par exemple le "monde développement de ces différents régimes conccurents nourrit un certain nombre de tensions, il apporte cependant une source de cohésion spécifique basée sur le fait que chacun de ces regimes régule des marchés monétaires. Ll'argent apparaît comme médiateur des sous le registre de l'altérité radicale. La consommation apparaît ainsi comme une forme de vie commune et l'expansion mercantile connecte marchés légaux et illégaux et contribue à nourrir la violence urbaine qu'elle est pourtant réputée contrôler.

Argent. Valeur. vue - ceux de la loi ou de la morale - seraient défini 